University of Nebraska - Lincoln

DigitalCommons@University of Nebraska - Lincoln

Management Department Faculty Publications

Management Department

2020

"Untact": a new customer service strategy in the digital age

Sang M. Lee

DonHee Lee

Follow this and additional works at: https://digitalcommons.unl.edu/managementfacpub

Part of the Business Administration, Management, and Operations Commons, Management Sciences and Quantitative Methods Commons, and the Strategic Management Policy Commons

This Article is brought to you for free and open access by the Management Department at DigitalCommons@University of Nebraska - Lincoln. It has been accepted for inclusion in Management Department Faculty Publications by an authorized administrator of DigitalCommons@University of Nebraska - Lincoln. 


\title{
"Untact": a new customer service strategy in the digital age
}

\author{
Sang M. Lee ${ }^{1}$ and DonHee Lee ${ }^{2}$ \\ 1 College of Business, University of Nebraska-Lincoln, Lincoln, NE, USA \\ 2 College of Business Administration, Inha University, 100 Inharo, \\ Michuhol-gu, Incheon, South Korea
}

Correspondence: DonHee Leedhleeo4@inha.ac.kr ; Sang M. Lee slee1@unl.edu

\begin{abstract}
The Industry 4.0 era has brought a shift in consumers' purchasing behaviors from traditional retailing to online and/or mobile channels, triggered by advanced digital technologies and an easy access to the global market. Smart digital devices and advanced technologies have enabled "untact" service, facilitating customer encounters without a face-to-face contact with employees. This study presents the concept of untact service based on a review of the literature on technology-enabled customer encounters with service providers and analysis of several real-world cases. The results indicate that untact services are becoming widespread in various areas of daily life, such as ordering food at franchise restaurants via digital devices, handling financial transactions without visiting a bank branch through e-banking apps, and using online or mobile order systems for a multitude of products/services. This study elaborates implications of untact service in terms of new opportunities and challenges involved when it is implemented as a new customer service strategy.
\end{abstract}

Keywords: Industry 4.o, Digital age, Untact service, Untact technologies

Published in Service Business 14 (2020), pp 1-22.

doi:10.1007/s11628-019-00408-2

Copyright (C) 2019 Springer-Verlag GmbH Germany. Used by permission.

Submitted 5 August 2019; accepted 29 August 2019; published 7 September 2019. 


\section{Introduction}

The digital age is characterized by the unprecedented velocity of change in the business environment and seamless connectivity among the players in the value chain. Advanced digital technologies are the main driver of organizational innovation and new value creation opportunities (Lee and Lim 2018). Artificial intelligence (AI), machine learning, Internet of Things (IoT), smart robots, big data analytics, blockchain, virtual and augmented reality (VR/AR), 3-D printing, ambient cloud computing, scalable software, and mobile Internet are prominent technologies that are providing new opportunities for creating new customer value (Verleye 2015; Kim et al. 2018; Lee 2018b; Lee and Lim 2018; De et al. 2019). These technologies have greatly enhanced dynamic capabilities of organizations, allowing agility, flexibility, and adaptability to align corporate strategies to changes in the environment, especially for responding to the rapidly changing customer needs and preferences. Today, customers require more than just the traditional values of reasonable price, good quality, speed of service, and customization. They want to be at the center of value creation activities, seeking new experiences, participation in co-creation of shared goals, and hedonic properties like sense of beauty and security, flow, arousal, and recognition (Merlino and Raman 2013; Vargo and Lusch 2016; Bollard et al. 2017; Bordoloi et al. 2018; Lee 2018a, 2019).

The advent of digital devices has helped businesses accentuate their service dominant (S-D) logic, providing not only quality goods/services but also customized services that customers desire (Vargo and Lusch 2004, 2008, 2016; Xie et al. 2016; Bordoloi et al. 2018; Lee 2018b). As customers' preferences have substantially shifted from the traditional retailing to online shopping and mobile commerce (m-commerce), service encounters between the firm and customers have also changed profoundly (Bordoloi et al. 2018). For example, the total retail sales in 1999 exceeded \$3 trillion in the USA. Since then, however, the traditional retail sales have decreased significantly and many wellknown retailers have since disappeared (e.g., K-Mart, Circuit City, Toy $\mathrm{R}$ Us, Blockbuster, etc.) or in dire financial difficulties (e.g., Sears, JCPenney, Neiman Marcus, etc.). In 2017 alone, more than 8000 retail stores closed operations in the USA (Hwang 2019). The major causes 
for the bankruptcy or financial difficulties of retail stores include the impact of technological innovations such as unmanned autonomous stores [e.g., Coupang's "Rocket Delivery" service, which is the first direct commerce model in the world (Cho 2018), AI- and big-data-supported rapid online and mobile services offered by Amazon, Walmart, Starbucks, and Otto (MGI 2017), convenience stores staffed by smart robots, and chatbot-managed kiosks (Schneider 2011; Hwang 2019)].

Today, businesses have the big-data-supported knowledge base on their customers' needs, preferences, routines, and even emotional states (Lee 2018a). The traditional concept of good-quality customer service by friendly salespersons has become the minimal requirement to attract customer attention. Now, customers demand customized services that support their taste, needs, and lifestyles (Lee 2018b; Lee and Lim 2018). The technology-enabled innovation systems can provide such customized services. Netflix makes it possible for its customers to watch their desired movies on demand without worrying about paying late fees, and car rental service providers offer new customer experiences by offering both online and offline rental processes. FedEx is providing customized delivery service that allows people to track the delivery progress of their order, including real-time alerts, through a mobile app.

Technology-supported innovation can shift certain transaction task responsibilities from workers to customers. Task transference is not new. Many business firms have offered self-service, do-it-yourself (DIY), cafeteria style services, and unmanned information kiosks. What is new in the digital age is that the degree of transference has gone far greater than the traditional encounters. Today, customers do comparison shopping, order purchases, make payments, do actual pickups, and sometimes actually perform the encounter task for experience. For example, customers can use mobile apps to order groceries to Walmart for curbside pickup at a specific time, Starbucks customers in South Korea use "Siren Order" app to pickup their coffee at the drive-through counter which handles automatic payment wirelessly to the customer's account, and Amazon recently opened a convenience store with no human cashier in Seattle.

Customers have different preferences for service during the encounter depending on the type of help needed, personal knowledge about the product or service under purchase consideration, and even 
their psychological characteristics (e.g., extrovert/introvert). Many technology savvy customers search various information sources on the Web and often know much more about the various aspects of the interested product or service than friendly salespersons at the store. Busy professionals or homemakers prefer to spend as little time for shopping as possible without the interference of store employees. As the number of one-person households increases, these customers greatly value simplicity, efficiency, cost effectiveness, and time management (Lee and Han 2013). The one-person household customers often focus on personal experience, new fashion or trends, and the lifestyle of self-sufficiency (Lee and Han 2013; Zhao and Liu 2019). For this type of customers, a new customized service "untact" is born.

"Untact" is a portmanteau term created in South Korea by adding the prefix "un," which has the meaning of "no," to the word "contact" (Kim et al. 2018). Untact service refers to service that is provided without face-to-face encounters between employees and customers through the use of digital technologies. Untact service is usually initiated by the customer who desires a service without engaging in a personal encounter (Bordoloi et al. 2018). Many businesses already offer untact services, which is enabled by advanced technologies, such as automatic dispensers, self-service counters, e-banking, online purchasing and payment systems, and "unattended" kiosks. With the rapid spread of digital transformation among businesses based on AI, IoT, big data analytics, and smart sensors, untact service systems are expected to develop rapidly as well. The reasons are quite simple: untact service is a win-win proposition for certain type of customers and business firms. A significant portion of customers with "individualist" tendencies in modern society (e.g., busy professionals, single-person householders, and technology savvy self-sufficient young persons) welcome untact as an additional channel of service. For businesses, untact could also be a boon as it helps attract new customers while minimizing service delivery cost.

This study has the following objectives: (1) to examine the evolution of customer- centric service and task transference through a review of the literature, (2) to explore the drivers of the emergence of "untact" as a new service strategy, (3) to present some of the most successful real-world examples of untact services, (4) to analyze the opportunities and challenges involved in implementing untact service, and (5) 
to elaborate implications of untact service and some of the key future research needs to support untact as a competitive strategy.

The rest of this paper is structured as follows. In Sect. 2, we present a thorough review of the relevant literature on service encounters, application of advanced technologies to support customized service, and the evolution of untact services. Section 3 presents several successful real-world examples of untact services today. In Sect. 4, we articulate opportunities to improve corporate competitiveness through untact service, as well as challenges that need to be overcome in implementing untact. We conclude the study in Sect. 5 by discussing implications of untact service as a corporate strategy, limitations of this study, and future research needs.

\section{Literature review}

The conventional concept of good customer service involves pleasant and effective face-to-face encounters between salespeople and customers. This view is changing due to advances in digital technologies. Today, AI technology is widely applied across most industries, especially in services. The widespread application of digital technologies has brought major changes in customer purchasing behavior (e.g., online and offline shopping, logistics and payment preferences, financing, etc.). The customer's multichannel purchasing behavior also requires a change in the way the provider's delivers value and experience to customers.

\subsection{Customer-centric strategy in the digital age}

Corporate strategies have gradually shifted from goods-dominant (G-D) logic to service- dominant (S-D) logic and from a supplier-oriented perspective to a customer oriented one, thus cementing the central role of service in the economy (Bell 1976; Lee et al. 2007). G-D logic focused on distribution mechanisms for service provision (Vargo and Lusch 2008), while S-D logic emphasizes a unique expression of value for economic exchange between firms and customers (Vargo and Lusch 2004). In addition, S-D logic is one of the most important theories to explain value co-creation through interactions between firms 
and customers because value is transferred from firms to customers (Vargo and Lusch 2004, 2008).

Recently, an individual's quality of life is increasingly determined by the availability of services (Xie et al. 2016). A service is described as an economic activity that creates a certain value for a customer or provides benefits to the user (consumer) at a specific place and time through the acts or performance of the provider (Xie et al. 2016; Bordoloi et al. 2018). As S-D logic combines activities between firms and customers as resource integrators (Lusch and Nambisan 2015), a service is a time-perishable intangible experience performed for a customer acting in the role of a co-producer. Thus, service companies seek strategies to identify customers' needs and enhance performance at service encounters through advanced technologies.

Theory of service encounter was first proposed by Shostack (1985) who classified service contact into three types (face-to-face encounter, indirect encounter, and remote encounter) and defined it as a period of time during which a consumer directly contacts and interacts with a service. Solomon et al. (1985) and Guiry (1992) proposed a service contact structure (customer-technology-provider), which was later generalized by Bitner (1992). Bitner (1990, 1992) defined a service encounter as a personal interaction that influences business performance. In addition, he classified the types of service encounters into two main categories: person-person and person-environment. Froehle and Roth (2004) classified service encounters into five types: technology-free, technology-assisted, technology facilitated, technology-mediated, and technology-generated. Lee (2018a) classified the technology-based forms of contact during the service encounter (where the service is performed by the customer alone or with the support of machines or AI) into three types. The first is a technologyfacilitated service, in which the customer and service provider complete the service together using AI robots or machines. The second is a technology-mediated service, where the customer interacts only with a screen using an AI robot or machine without direct contact with the service provider. The third type is a technology-generated service, in which the customer voluntarily creates and completes the service using AI robots or machines. These studies indicate that technology can be used to gradually reduce the interaction between the customer and the employee. 
With the world-leading digital technology diffusion, South Korea has introduced numerous technology-based service types. Since 2018, many service encounters between customers and employees began to shift to untact. An untact service is the one that involves no face-toface interaction between employees and customers, supported by advanced technologies. This technology-based service represents a new operating model for service encounters (Bordoloi et al. 2018; Kim et al. 2018; Lee 2018a).

\subsection{Evolution of task transference and "untact" service}

Task transference refers to shifting some of the transaction tasks from employees to customers. Evolution of transference has been influenced by economic and technological development during the past 70 years or more. In general, there are three stages of transference evolution.

\subsubsection{Post-World War II (WW2) economic development stage}

The explosive increase in productivity and an economic boom in the post-WW2 period saw supply of products exceeding demand for the first time (Lee et al. 2007; Ryan et al. 2011). Many new marketing strategies and promotion approaches were developed: massive advertisement campaigns, customer-centric strategies, and analysis of consumer behavior. Thus, customer convenience, customer service quality, and after-sale services became popular. Thus, 24/ 7 customer service ideas created many vending machines, convenient self-service counters (soda, candy bars, coffee, sandwiches, etc.), and answers to frequently asked questions.

\subsubsection{Advanced technology development stage}

With the advanced ICT, mass media (TV, radio, and Internet) became the vehicles for engaging customers, build brand loyalty, set up membership clubs, etc. Speedy data processing technologies made it possible to implement market segmentation and market differentiation strategies (Ryan et al. 2011; United Nations Secretariat 2018). Thus, the idea of the S-D logic came as a reality. As customers demand 
not only the convenience and quality of service, but also the type of service they prefer, speed of service became important. Thus, "Do It Yourself" emerged as an important marketing strategy. Electronic games without an opponent to play against became possible for card games, board games, sports, and mental games (e.g., chess).

\subsubsection{Advanced digital economy development stage}

In the advent of the Fourth Industrial Revolution (4IR) and the digital age, advanced digital technologies have changed the way people live and organizations function. AI, machine learning, IoT, smart sensors, robots, 3-D printing, and others have made it feasible to turn what is probable into possible (Lee 2018b; Lee and Lim 2018). Thus, convergence of creative ideas and digital technologies has enabled exponential innovation for digital services. Today, customers handle their own banking service, shop and make payments, and check own vital signs for healthcare service.

"Untact," a creative marketing strategy sprung in the most advanced digital economy of the world, South Korea, is to provide customers with two new services: (1) for customers who prefer not to have any face-to-face contact with service employees, they have a new choice of DIY; (2) for digital savvy customers, intact service does not only fit with their own style of living but it also allows speedy and quality service. For organizations, untact marketing provides many benefits as well. Some of the obvious ones are: (1) expanding the market base as it helps attract new customers who normally would not be attracted to the firm's products or services; (2) untact marketing saves a great deal of workforce serving customers; (3) untact marketing accelerates the service pace, thus increasing the sales volume per unit of time; (4) untact marketing would increase customer loyalty as it offers an additional choice of service to customers; and (5) untact service most likely would reduce the volume of customer complaints and after-sale service demands.

\subsection{Untact technologies}

Online platforms such as social media have altered the culture of communication as well as the way people interact with each other (Horn et al. 2015; Amar et al. 2019). With the activation of online 
platform-mediated single-person media, the usage of YouTube and Creators is growing rapidly, and collaboration between a firm and personal broadcasting service provider is also increasing. As such, the digital age is changing not only the way firms communicate with consumers but also the culture of sales (Bollard et al. 2017; Kim et al. 2018, 2019). The environment in which products/services purchases are performed is shifting toward untact encounters. In an untact environment, since transactions do not require human interaction, value is created directly by the consumer using digital device or technology (Lee 2018a).

Online connectivity through advanced technologies and platforms such as AI, robots, IoT, and big data creates value without the need for people to directly interact with each other (Bollard et al. 2017). Furthermore, untact service types are gaining prevalence as the number of people who feel uncomfortable or inconvenient with human relationships is increasing (Sweeney et al. 2015; Verleye 2015; Lee 2019). It is becoming increasingly common for companies to use untact technology to sell products and services without face-to-face encounters with customers. With the advent of $4 \mathrm{IR}$, radical technological innovation is enabling change, not only within businesses but also consumers' concept of quality service.

Kim et al. (2018) drew attention to the rise of unattended service types and untact technology in their Trend Korea 2018 study. The authors suggested that untact services go beyond simple unattended or non-face-to-face technologies because they provide adaptive and personalized services (Kim et al. 2018). Untact services provided through mobile applications offer services that were previously only possible through face-to-face interactions. In Japan, the "silent customer service" trend is also growing and spreading fast. In both countries, new business models are emerging based on the feedback of shoppers (e.g., "I felt nervous when the salesclerk talked to me") and in the local transportation service "Silence Taxis" have been introduced (Kim et al. 2018). Such new business models create value by shifting human-human relationships to human-technology relationships. Service models applying untact technology have emerged to fit this trend (Verleye 2015; Lee 2018a).

While some untact service types existed in the past (e.g., telephones and call centers), they are different from currently popular service types. To provide rapidly changing untact services, companies need to 
learn how online systems (their characteristics, information, and design) affect customer behavior. Using this knowledge, they can develop appropriate operational strategies. In this regard, De et al. (2019) proposed that the following questions should be addressed: What drives the effect of search technology on sales? How can economic returns be derived from recommendation systems? Why is it important to separate product facts from product impressions to control returns? How can the digital traces left by consumers be leveraged to generate benefits?

Due to the increasingly active use of social media and the spread of the Internet and mobile technology (Amar et al. 2019), now consumers can easily find what they need without the help of an employee, thus decreasing the need for contact and promoting the spread of untact technology. Consumers have reacted positively to untact technology, and new business models reflect customers' preference for a "comfortable cut-off" from communication over "uncomfortable communication" (Kim et al. 2018). Many young consumers who are accustomed to digital devices tend to feel uncomfortable around people and prefer "solo shopping" (Kim et al. 2018). According to Kim et al. (2018), cost reduction, immediate satisfaction, abundant information, and interpersonal fatigue are the main drivers for the proliferation of untact technology in the market.

In addition, Kim et al. (2018) suggested the following four major avenues of value creation offered by untact technology: (1) quick service at any time: customers dislike complicated procedures or waiting and want to receive services at any time. An example of this type of value creation is the "smart unattended laundry drop-off box" installed by 7-Eleven that allows users to drop off their laundry 24/7. When the user delivers the laundry and inputs personal information on the touch screen, the laundry service is automatically initiated. After the clothes have been cleaned, the customer is notified via text message for pickup at a convenient time. This approach can create value for both the customer and the business (reducing the cost of labor and management); (2) convenient and in one go: customers dislike having to visit multiple destinations to purchase goods and services. For example, similar to Amazon Go in the USA, Alibaba introduced “Tao Café," an unattended convenience store that conveniently handles processes from searching for information on products to payment. Users install the Taobao app on their smartphone, create an account, visit 
Tao Cafe, search for the required product, select the product, and register. Then, the automatic exit opens, the product is scanned, and payment is processed. This is an example of an untact convenience store in which customers can purchase products by only using the Taobao and Alipay applications; (3) without anyone knowing for privacy and secret: many people are reluctant to expose their private lives to the outside world. Personal information, such as video images, location, and biometric information are often shared, thus generating increasing concerns about privacy and security. There is an increasing demand for services that can alleviate these issues. For example, an individual can buy a book online and read it on a Kindle. Then, no one knows what book the person bought or is reading. Protecting one's privacy is essential in the digital age and untact services make this possible, value created without direct interactions; and (4) just for me: as untact technology is based on big data and AI, customers can receive customized services tailored to their preferences. Thus, customer satisfaction can be improved without direct interaction with the service provider (Kim et al. 2018; Lee 2018a).

Digital kiosks have been available since around year 200o. Today, services based on untact technology are available in various fields, such as cosmetic shops, cafes, restaurants, banks, and delivery. The normalization of untact services is expected to increase consumer comfort with and preference for technology. Thus, consumer purchase activities are expected to gravitate toward online platforms that do not require offline stores. This is in line with the general trend of the increasing online and mobile shopping, the development of AI-based services, and the spread of unattended stores. As consumption trends shift to non-contact service types based on untact technology, these new systems need to reflect generational and social changes.

Untact technology can be regarded as advanced technologies and platforms to create value for customers in line with the trends of the digital age, such as customer- centric management, the S-D logic, and consumers' desire to avoid hassle and receive timely, quick, and excellent service (Lee 2018a, 2019). In addition, untact technology can accommodate the demands of customers who feel more at ease with the Internet and $\mathrm{m}$-commerce than those who are technologically challenged. Companies that focus on customer-centric management need to find ways to indirectly contact their customers when they prefer not to be contacted by employees. The S-D logic proposed by Vargo and 
Lusch $(2006,2008,2016)$ suggests that if the value generated by the interaction with the customer is more important than the value provided by the product or service itself, such interaction needs to carefully consider the characteristics of the service (e.g., intangibility, simultaneous perishability, and heterogeneity). For instance, customers who are familiar with digital devices tend to prefer solo shopping to shopping based on interactions with staff. Therefore, according to the S-D logic, indirect interaction with customers can be expanded by providing digital device functionalities (apps) that empower customers to generate value for themselves, without interaction with employees.

Untact technology enables services that are provided in a non-faceto-face format without contact with people (employees-customers) as showcased by the Amazon Go convenience stores, Tao Cafe shops, laundry drop-off box service, chatbot staffed kiosks, and Starbucks Siren Order app in South Korea. Technologies that enable untact service systems are AI, machine learning, IoT, VR/AR, big data analytics, smart sensors, smart robots, and the platform built with these technologies. As technologies that substitute human contact with machine interactions spread, customers are experiencing a digital wave. If customers feel discomfort when interacting with other people during a service encounter, the service model needs to be changed from direct interactions to an intangible service-based model that uses technologies to replace human helpers (Lee 2018a). Therefore, untact technology can be seen as a form of digital transformation where the service paradigm is shifted from the customer interaction focus to intangible interactions based on advanced technologies.

\section{Real-world examples of untact services}

With the rapid diffusion of digital technologies in daily routines of people, untact service has gradually become an essential element of value that customers expect from service providers. In this section, we present and discuss several real-world examples of untact services.

\subsection{Internet banking}

A direct bank is a bank without any branch that provides its services entirely via online and mobile devices. While banks already offer 
financial services online and through mobile applications, the customer must visit a branch to open an account or request a loan. However, the recently introduced concept of a pure Internet-based bank enables users to perform all bank-related tasks online.

A pure Internet bank, K-Bank, was launched in South Korea in April, 2017. On the first day of service, 36,000 new accounts were opened, equal to the average number of new accounts opened at 16 different banks in Korea over a 3-month period. ${ }^{1}$ While consumers may have had several reasons for choosing an Internet bank (high interest rates on deposits, low loan interest rates, and low service fees, among others), the avoidance of space-time constraints and the convenience of easy services are likely to have played significant roles (Sindwani and Goel 2015). Internet banks operate 24/7 all year around. Major channels to operate service activities include smartphones and ATMs, and customers can register with the bank using their ID. Customers requesting a loan can be screened for eligibility directly via their smartphones. Internet banks are expected to grow larger than conventional offline banks mainly because of the better interest rates they can offer (Xue et al. 2011). This phenomenon indirectly suggests that the group of consumers who finds untact service convenient has increased. As the number of untact service users increases, mobile based services are taking hold not only in terms of online banking but also for international transactional banking.

To address the large number of foreign workers in South Korea, "Sentbe," a fintech money transfer service startup launched in 2015, offers real-time overseas remittance service to 17 countries and a variety of other banking services at relatively low fees. ${ }^{2}$ This business model is still in an early development stage. Thus, companies that are interested in this business model should also explore various other operational strategies to succeed with this type of innovation. In particular, as the core competitiveness of finance firms lies in their ability to analyze individuals' creditworthiness through technology such as $\mathrm{AI}$ and machine learning, being competitive in dealing with digital platforms is essential (The Korea Economic Daily 2019).

1 K-Bank: https://www.kbanknow.com/ib2o/mnu/PBKMANoooooo.

2 Sentbe: https://www.sentbe.com/en. 


\subsection{Online counseling}

Today, mobile psychological counseling is spreading rapidly as more people are struggling with mental health issues such as depression and panic disorders in the breakneck pace of the digital age (The Korea Economic Daily 2019). Millennials (those born in the early 1980 s to the early 200os), who are familiar with mobile technology and tend to prefer untact services, often receive psychological counseling through mobile applications. The following is an example of a consultation over a mobile psychological counseling application: Consultation Customer: "I have been working for 5 years. I am being greatly hurt by personal attacks from my superior. As this is my first job, I didn't have the courage to transfer and tried to bear the attacks. Lately, however, I cry every day and have no motivation." Psychological counselor: "As this is your first job, I am sure you are putting your best efforts in your work. However, while changing departments or switching jobs won't be easy, continuing to bear this treatment is not the right solution." The mobile application provided this consultation. Typical users include those who have no time to visit psychological counseling centers or find face-to-face counseling uncomfortable, and 80\% of consultation consumers are aged 25-34 years.

"Trost," a mobile psychological counseling application that uses untact technology, has been downloaded more than 50,000 times and provides mobile psychological counseling services for company employees in cooperation with enterprises. Another psychological counseling application, "Mind Café,” has nearly 500,00o members and also operates a "Mind Cafe Pro" business, in which professional counselors provide paid psychological counseling services (The Korea Economic Daily 2019). This form of online and/or mobile psychological treatment is expected to gradually become widely available due to the guarantee of anonymity and easy access to the counseling targets, with a relatively small financial burden.

\subsection{Cosmetics stores}

Cosmetic companies have been adopting combined online-to-offline (O2O) strategies as online purchasing has gradually become significant (Kim et al. 2018). These services offer an "online purchase 
+ offline experience." For example, "Innisfree," a cosmetics firm in South Korea, acknowledges that mainstream customers (teenagers and those in their 20s) often screen products through the Internet or mobile technology and then purchase in a physical store (Kim et al. 2018). Therefore, Innisfree provides two types of baskets in its stores: one that reads "I need help" and another that reads "I can do it myself." This strategy allows customers to shop more comfortably. These shopping baskets enable employees to focus on helping those customers who want and need support. Other customers can shop freely and without interruption by salespeople. This strategy is very popular among both employees and customers.

Innisfree also operates a "self-service store" in a popular shopping mall located in Seoul, with no employees, based on the implementation of untact technology. This store is mainly used by consumers familiar with digital devices, in their 10-30s, who prefer to shop without the help of a salesclerk. Smart high-tech devices in the store offer product information, location guides, customized product recommendations, and a self-payment system. Employees are available for customers who need assistance. The smart devices in this store include a "selfcounter" (for self-processing of payments and automatic packaging based on radio frequency identification technology), a "digital shelf" (for viewing brand experience videos and product details), "counseling kiosks" (for information on events, discount promotions, locations of in-store products, and information on best-selling products), and an AI chatbot for Q\&A sessions. A "face-mask vending machine" recommends face masks suitable for the customer's skin through a digital Q\&A session, and the "Beauty Talk Mirror" allows customers to check their skin condition and recommends the most suitable products to their skin type (CNC News 2019). ${ }^{3}$

Typically, when customers enter a cosmetics store, they are greeted by an employee at the entrance with "Is there something particular you are looking for?". When the customer selects a product after looking around, the employee often suggests "Product A you chose is fine, but lately Product B has been popular" or "Product C seems like a better fit for you." In this way, the employee entices customers to make a purchase. However, as some customers dislike interactions with 
employees and feel uncomfortable with such sales tactics, the popularity of untact technology is expected to keep increasing as the number of customers who are not only familiar with digital devices but also have good knowledge about available products based on their Internet search. These customers would prefer untact service, and their number is expected to increase exponentially.

\subsection{Car showrooms}

Are there car showrooms without cars and employees? Many automobile brand experience centers have been popping up as antact marketing strategy. Hyundai Motor Company opened the "Hyundai Motor studio Digital” in 2014 in Seoul (Hyundai operates four such stores in South Korea as of 2019), as well as two overseas (in Beijing, which opened in 2017, and in Moscow, opened in 2015).

At automobile brand experience centers, customers can experience driving virtual cars through digital content utilizing untact technology. Customers can choose a car model they would like to examine, with desired features and colors (both exterior and interior). Through the touch screen, customers create their own car, watching the car being manufactured in the assembly process through VR, and experience the size and sound of the real car through a large screen. In addition, a "3D Wall" allows customers to experience the 3D image of the designed vehicle, thus enabling consumers to experience every characteristic of the vehicle without it being physically present. Customers can freely view the car and seek help from a "Guru" (a professional staff member knowledgeable about Hyundai automobiles and the company culture) or receive purchase consultation in a separate area. ${ }^{4}$

\subsection{Silence taxis}

Miyako Taxi, which operates mainly in Kyoto, Japan, introduced a new taxi service "Silence Taxis" to provide customer-oriented service where the driver is prohibited from talking with passengers during the drive (excepted emergency situations) (Baseel 2017). Miyako Taxi started the service with five Silence Taxis operating on Kyoto streets. The company posted a notice on the back of the front passenger seat 
informing the passengers about the goal of "Silence Taxis." Miyako Taxi announced that "This service is currently in a trial stage, with the goal of creating an in-car atmosphere that provides the most comfortable ride for passengers through limiting the driver's speaking" (Baseel 2017). If passengers would like to be chatty with the driver, the Silence Taxi driver can oblige.

\section{Opportunities and challenges of untact service}

The nature of untact service depends on two factors: (1) the type of service needed and (2) whether the customer desires untact service or not. While untact service originated due to the customer's desire for no human contact during the encounter, certain services require and some customers desire staff assistance to receive the full extent of the service. If a service can be provided by any person or a new technological device, then such task will be a good candidate to be transformed into an untact service. On the other hand, if a service requires a skilled specialist or personal attention, then such service would continue to be a manned or live-person encounter (ILO 2010). Even for a general service, certain customers may prefer untact encounters from the service provider. For example, technology savvy netizen travelers avoid a long queue at the airport check-in counter by using a mobile app for online check-in and unmanned motels in resort areas that provide untact service are popular among celebrities and public figures who do not wish to be seen by many people. As any new innovation, untact service has both positive (offering new opportunities for improving competitive advantage) and negative (challenges that cause new burdens or cost to the firm) aspects.

\subsection{Opportunities for improving competitive advantage}

In the digital age, business firms need 3 Vs to improve their service competitiveness: velocity, value creation, and voice communication. Velocity represents the ability to quickly respond to changing customer needs for service. Today, service competition is often among platforms of companies (Xie et al. 2016; Amar et al. 2019). Consumers' demand for traditional and new values from service changes rapidly. Consequently, firms need to apply advanced digital technologies 
to improve their dynamic service capabilities to adapt to the changing environment with agility, speed, and adaptability (Lee 2018b; Amar et al. 2019). For example, firms may develop omnichannels (e.g., bestin-class digital and live-person channels) to retain their current customers on their platforms, even when the customers cross over online and offline in search of the best services they desire as shown by Amazon, Spotify, and Google (Hedwig et al. 2019). While O2O (online to offline) is for connecting online to offline, $\mathrm{O}_{4} \mathrm{O}$ (online for offline) is a platform service which leverages online data to enhance offline business (Kim et al. 2018; Korea IT Times 2019). The best example of $\mathrm{O}_{4} \mathrm{O}$ platform service would be Amazon's new offline bookstore in New York City (Kim et al. 2018; Korea IT Times 2019). This store utilizes the big data of Amazon users to select and display only those books that have over 10,000 reviews and online rating of over 4.8/5.o. This offline bookstore has no cashier but an online autonomous payment system (Kim et al. 2018).

Value creation is about service capability to create value that the customer desires. A firm cannot develop competitive advantage by offering the same type or quality service as its competitors. Thus, a differentiated or unique service must be offered, as today's consumers use smart devices to compare the various products or services before making their purchase decision. As untact service has become widely available, the manned encounter can be differentiated as premium service rather than free service. This strategy will allow a firm to improve its competitive advantage by securing the customers who prefer the premium manned encounter and also attract those who desire untact service. For example, as discussed earlier, Hyundai Motors Studio Digital offers potential customers to experience driving a new model on the VR vehicle and those with questions can have a face-toface service with a Guru, an expert on the Hyundai culture and vehicles (Hyundai Web site).

Voice of communication is about the communication environment with customers. In order to understand the needs or desires of customers, the firm must have the capacity to listen to customers and respond accordingly. Customers' needs change quickly, thus the firm should develop a complete self-managing system to process such data and respond autonomously (Horn et al. 2015; Xie et al. 2016; Lee 2018b). To make such system effective, customers should be involved from the design phase of the product or service to final selling 
and after-sale services. With the advanced digital technologies and social networks, the communication environment between the firm and customers can be organic. With AI, machine learning, and big data analytics, individual customers' personal interests and preferences can be customized. In the process, differentiated services can be provided to segmented markets for either untact or premium manned encounters.

In addition to attracting a new class of customers, untact service can greatly improve the value chain in several ways. In the value chain, a business firm can implement innovation to create value in five main areas: developing new products/ services/ventures, redesigning the value chain architecture to improve its efficiency (e.g., greater speed, disintermediation, outsourcing, or co-innovation), creating new customer value through differentiation and customization, expanding the customer base by creating a new market, and introducing new business models (Lee and Olson 2010). Among these five areas, untact services can provide most value-creating opportunities in the following three areas: reinventing the value chain, creating tailored customer value, and expanding the market base. New value creation can help the organization improve its competitive advantage.

\subsubsection{Streamlining the value chain}

The value chain efficiency can be improved through speeding up processes and minimizing personnel cost. An untact service system can streamline the customer encounters before and after sales (Amar et al. 2019). Thus, a separate value chain can be designed for untact service customers as their number increases significantly. The greater the proportion of untact customers, the greater the speed improvement in the value chain. In addition, untact services reduce the need for live-person encounters. Thus, the greater the proportion of untact service customers, the greater the personnel cost savings.

\subsubsection{Creating new customer value}

Untact service is not universally valuable to all customers. However, for a certain group of customers (technology savvy netizens, busy young professionals, many of one-person household dwellers, 
introvert persons, and/or public figures), untact service provides special value for simplicity, confidentiality, and time and cost savings. Thus, untact service is a tailored service specific for the interest of a special group of customers.

\subsubsection{Expanding the customer base}

The customer base includes local offline customers, e-customers who use online and mobile channels, and international customers (Lee and Olson 2010). Untact service can attract many new customers using the digital and platform channels. This is currently the fastest growing market segment in the digital age.

\subsection{Challenges of untact service}

While untact service promises to offer new opportunities to improve corporate competitive advantage, it also has a number of challenges that must be effectively managed. Some of these challenges are based on mega trends of the digital age, and some are manageable by individual organizations. The most difficult challenges facing untact service are as follows.

\subsubsection{The untact divide}

The digital divide is a global issue. The advanced digital technologies have become part of everyday routine for most organizations and individuals. However, there are more than four billion people who live in the digital darkness without the Internet access (Luxton 2016; Word Development Report 2016). These people have no opportunities to receive global or local news and communicate with others through e-mails, Instagram, or other social network services. Even for those who have digital devices available, using untact service may be a difficult task. Untact service can be a useful channel only when the user utilizes digital devices. Thus, the "untact divide" can be a major barrier to the widespread use of untact service, especially for those who find the process of using digital devices too cumbersome. Many senior citizens, international customers with limited foreign language proficiency, and those who have negative predisposition about online shopping would belong to this group. 


\subsubsection{Cybersecurity}

Untact service can provide convenience and time savings to many customers. However, using this channel demands release of some personal data. Thus, the issue of privacy and data security is a real challenge. Cyber hacking can paralyze the untact system of a firm, and/ or it could release personal data of untact customers. Consequently, digital enterprises must build cybersecurity as a core feature of their value chains (Kaplan et al. 2019).

\subsubsection{New customer complaints}

Many untact services are provided through virtual shopping environment where customers view goods or services online or based on VR/AR. After the purchase, some customers may find the received goods/services are not what they expected. Thus, customer complaints or dissatisfaction may result due to either false information provided by the firm or misunderstanding on the part of the customer. Untact service is not for every firm or every customer. It should be carefully designed for certain type of customers at specific phase or aspect of shopping. If a firm uses only recorded messages of a virtual receptionist to respond to customer inquiries, it can create a new cause of customer complaints (Horn et al. 2015).

\subsubsection{The role of technology in untact service}

While technology enables untact service, it also eliminates personto-person contact (Kim et al. 2018; Lee 2018a). Value creation used to be based on the customer centric philosophy (Vargo and Lusch 2004, 2008). However, advanced technology supported untact service has become a new venue of value creation. Nevertheless, even for untact service the ultimate center of the concept is still people, a group of specific type of customers who prefer no direct live-person transaction encounter. Thus, for a successful untact service implementation, it is imperative to achieve ambidexterity between contact-based value creation and untact encounter-based value creation. Even for untact service, the firm must devise the best way to interact with untact customers (Horn et al. 2015). It is difficult to select the best available technologies to support untact service because of the fast pace of technological advances. 
4.2.5 Information overload and abuse of the untact service system

The digital age provides the various sources of information and intelligence to the organization, consumers, and society at large. To facilitate untact service, the firm must provide a sufficient amount of information to potential customers through various channels. However, too much information, especially confusing or misleading kind, can be a source of frustration to customers. On the other hand, untact service has the vulnerability to abuse by professional hackers (Castillo 2018; Cheatham et al. 2019). Thus, the firm should have an effective risk management system for untact service, including the vigilance for new technological advances that can help prevent such risk.

\section{Conclusions}

In this study, we examined how advanced digital technologies have altered customer purchasing behavior, and in the process, untact has become a new strategic approach to delivering new value and experience to the customer.

\subsection{The brave new world of untact service}

The Internet-enabled services and social media have dramatically increased in recent years. Thus, consumers now rely less on information provided by brands and suppliers (Lee and Han 2013; Horn et al. 2015; Amar et al. 2019; Kim et al. 2019). This change in the purchasing environment has become the fundamental driving force in nudging consumers toward more value-oriented behaviors (Lee and Han 2013; Kim et al. 2018, 2019). The future consumption culture and customers' lifestyles are expected to become more fragmented and reflect the influence of digital devices (Lee and Lim 2018).

Untact services, an innovative type of service that is changing the lives of consumers, are rapidly penetrating various fields. While employee-customer interactions are not completely obsolete, a significant share of face-to-face services is expected to be replaced by untact services in the future. In particular, $\mathrm{O}_{2} \mathrm{O}$, which is a phenomenon that combines online and offline, is evolving to satisfy the requirements of consumers who want to enjoy shopping under optimal conditions 
across boundaries (Afuah and Tucci 2001). As chatbots and AI become more sophisticated, customers begin to rely more on digital devices than human staff, making untact technology a key feature of $\mathrm{O} 2 \mathrm{O}$ strategies (Horn et al. 2015).

While it is generally accepted that untact technology will drastically change the consumption culture, not all aspects of this new culture are necessarily positive. The positive aspects of untact technology include the reduction in labor costs, increased comfort and convenience to customers, immediate access to product/service information, diverse buying experiences, and the transfer of certain responsibilities to the customer. The negative impacts include the decrease in human interaction, job loss, alienation of senior citizens who are mostly unfamiliar with the digital environment, and the increase in single-person economic subjects (Kim et al. 2018; De et al. 2019). Considering these negative aspects, there is also a need for continued attention and care of groups who are disadvantaged in terms of their access to information.

Converting services to a digital environment will not only enhance convenience but also lead to customer-oriented value creation. This will be an essential factor for companies to obtain a competitive advantage in the future. While untact technology has already become part of our lives and spread to various fields, the potential for expansion is still vast (Kim et al. 2018). Untact technology is expected to spread exponentially, with the increase in consumers who wish to make decisions quickly and conveniently on their own and without contact with others (Kim et al. 2018; Lee 2018a). However, some consumers still prefer direct interactions with others. As value cannot be created by merely excluding humans, face-to-face services should not be discarded. According to a study by Fetch, the mobile-first media agency in the USA, $24 \%$ of people reported that chatbots exacerbate their dissatisfaction when they are angry or unhappy (Duduskar 2017).

In this regard, Kim et al. (2018) predict that human services will generate a significant premium as untact technology develops and expands.

Radical changes in service types also necessitate innovative business models. In particular, as consumer demands diversify, judging when and how to choose "contact" or "untact" strategies will become essential to create value through technology. From this perspective, 
new business models will need to ensure that core values of customeroriented service (including convenience, economy, novelty, differentiation, personalization, speed, and diversity) are delivered in order to build an effective digital untact ecosystem.

\subsection{Implications of untact as a strategic competitive advantage}

Business firms should develop and test various operational strategies to improve competitiveness through untact technologies, as suggested by the examples presented in this study. With servitization becoming the essence of products in all industries and distribution paradigms also changing fast (Baines et al. 2009; Bordoloi et al. 2018), untact service as a new transference strategy has spread widely. In addition, the digital era is rapidly shifting the dominance of the market to consumers as the consumption pattern has changed to favor omnichannels that blur online-offline boundaries (Kim et al. 2019). Given the rapid pace of change in the business environment, there is a need for a comprehensive analysis of characteristics of customers including their preferences of media utilization, service encounters, and channels. Thus, we suggest the following implications of untact service as competitive advantage in the digital age.

First, general consumers should be provided with the opportunity to adapt to the rapidly developing digital environment. Opportunities for experiencing untact service through digital technology should be widely available. Poor customer experience should be minimized to earn consumer trust and encourage them to continuously search for the type of service they desire. Education and training opportunities for older consumers should be provided to reduce their aversion of the digital lifestyle (Lee 2018a).

Second, customer-oriented strategies should be developed considering customer characteristics, geographical locations, and the conditions of the business environment. Differentiated strategies should be provided through specific brand advertisements on portals, news articles, and online communities, and using real-time updates to analyze customers' behavioral patterns, preferences, and experiences (Lee et al. 2019). For example, a customer who used Amazon most likely would have been exposed to Amazon's "recommended products." Amazon collects and analyzes data, while customers browse the Web site and make purchases. In this away, Amazon can predict what customers 
would want and when, based on recommendation technology and big data. This service presents customers with the opportunity to purchase the recommended products through Amazon.

Third, as untact service is driven by customer's active participation, companies should devise programs that encourage customers' participation. Customers are likely to prefer traditional purchasing channels if they find the technology or device too complicated to use. To achieve success with new service, the focus should be on the interface or technology and user interactions. The consumer's intention to use a service depends on how easy and convenient the system or associated device is (Kim et al. 2018; Lee 2018a). Companies must provide programs and applications that are easy and convenient. In addition, companies should provide easy new programs and/or apps linked to the existing services so that the new service platform encourages continuous usage.

Fourth, the overwhelming amount of information that may burden the customer experience should be filtered to only provide what is required, and contact and untact service methods should be appropriately combined to increase customer satisfaction. In the contact-untact service methods, professional staff, chatbots, and AI robots may be part of the service encounters.

Finally, companies should provide experiential services, which generate value via a pleasant experience and leave customers with a positive image that will influence their intention to reuse a service in future and word-of-mouth promotion of the service.

\subsection{Limitations and future research needs}

This study has presented the concept and evolution of untact service as a new customer service strategy. We also provided several realworld cases, thus filling a gap in the academic literature. While untact service is currently being provided in various industries, we expect the cases discussed in this study would help determine the best type of operational strategy to implement in order to create sustainable competitive advantage through untact service.

This study has some limitations. First, untact service is new and its theoretical foundation has yet to be firmly developed. Thus, our review of the literature presented the foundations of customer-centric management, service-dominant logic, and digital technologies that 
are the drivers of untact service. We provided real-world cases of untact services available today. While they are innovative services, they are not rigorously supported by the literature due to the lack of accumulated knowledge of this new type of service. Thus, the causal relationship between untact service and competitive advantage of the firm remains to be proven through empirical research. Second, as untact technology must be applied to human-machine encounters through convergence or collaboration of technologies and functions, a careful analysis of the characteristics of the product or service should be undertaken before the actual application of technologies. For example, while untact technology may be applied at a rate of $80 \%$ for product selection in a cosmetics store, it may need to be applied at a rate of 40-50\% in a car dealership. Moreover, untact service in different industries or products/services would require different digital technologies at different utilization ratios. Thus, continuous empirical studies would provide more accurate data and information to devise the best operational strategy for untact services. Third, because human resources must be invested in to enhance customer experience in contact-untact services, future studies should also investigate how to best utilize human resources in different service categories. Lastly, further study is needed to clarify at which stage in the value creation process technology-based service encounters can best be applied.

Acknowledgements This research was supported by the Ministry of Education of the Republic of Korea and the National Research Foundation of Korea (NRF-2018S1A3A2075240).

\section{References}

Afuah A, Tucci C (2001) Internet business models and strategies: text and cases. McGraw-Hill, New York

Amar J, Raabe J, Roggenhofer S (2019) Customer first: personalizing the customer-care journey. McKinsey \& Company, New York

Baines T, Lightfoot H, Benedettini O, Kay J (2009) The servitization of manufacturing: a review of literature and reflection on future challenges. $\mathrm{J}$ Manuf Technol Manage 20(5):547-567

Baseel C (2017) Kyoto 'silence taxi' service prohibits drivers from instigating small talk. RocketNews24. Japan Today, April 9. https://japantoday.com 
Bell D (1976) The coming of post-industrial society: a venture in social forecasting. Basic Books, New York

Bitner M (1990) Evaluating service encounters: the effects of physical surroundings and employee responses. J Mark 54(2):69-82

Bitner M (1992) Servicescapes: the impact of physical surroundings on customers and employees. J Mark 56(2):57-71

Bollard A, Larrea E, Singla A, Sood R (2017) The next-generation operating model for the digital world. McKinsey \& Company, New York

Bordoloi S, Fitzsimmons J, Fitzsimmons M (2018) Service management: operations, strategy, information technology, 9th edn. McGraw-Hill, New York

Castillo M (2018) Facebook security breach allowed hackers to control the accounts of up to 50 million users. CNBC. https://www.cnbc.com/2018/og/28/ facebook-says-it-has-discovered -security-issue-affecting-nearly-50-milli onaccounts-investigation-in-early -stage s.html. Accessed 28 Sept 2018

Cheatham B, Javanmardian K, Samandari H (2019) Confronting the risks of artificial intelligence. McKinsey \& Company, New York

Cho C (2018) Coupang's rocket delivery reaches 1 billion mark in 4 years. The Korea Herald. http://www.korea herald.com/view.php?ud=20180 920000729. Accessed 20 Sept 2018

CNC (Collaboration and Cosmetic) News (2019). March 5, http://www.cncnews. co.kr $/$ news $/$ article.html? $\mathrm{no}=4600$

De P, Hu Y, Rahman S (2019) Avoid these five digital retailing mistakes. MIT Sloan Management. https://sloanreview.mit.edu/article/ avoid-these-five-digital-retailing-mistakes/

Duduskar A (2017) Tech-obsessed American are more impatient today than five years ago. MARTECHSERIES. https://martechseries.com/mobile/apps-forbusiness/tech-obsessed-americansare-more-impatient-today -than-five-years -ago/. Accessed 7 Aug 2017

Froehle C, Roth A (2004) New measurement scales for evaluating perceptions of the technology-mediated customer service experience. J Oper Manage 22(1):1-21

Guiry M (1992) Consumer and employee roles in service encounters. Adv Consum Res 19:666-672

Hedwig M, Friedsdorf M, Goryunov Y, Niedermann F (2019) Omnichannel consumer interactions: a payer perspective. McKinsey \& Company, New York

Horn I, Taros T, Dirkes S, Hüer L, Rose M, Tietmeyer R, Constantinides E (2015) Business reputation and social media: a primer on threats and responses. J Direct Data Digit Mark Pract 16(3):193-208

Hwang J (2019) The future of retail business. Influential, Seoul

INO (International Labour Office) (2010) A skilled workforce for strong, sustainable and balanced growth: a G2o training strategy. International Labour Office, Geneva

Kaplan J, Richter W, Ware D (2019) Cybersecurity: linkpin of the digital enterprise. McKinsey \& Company, New York 
Kim R, Jeon M, Lee H, Choi J, Lee J, Kim S, Lee S, Seo Y, Kwon J (2018) Trend Korea 2018. Miraebook Publishing Co., Seoul

Kim E, Libaque-Saenz C, Park M (2019) Understanding shopping routes of offline purchasers: selection of search-channels (online vs. offline) and searchplatforms (mobile vs. PC) based on product types. Serv Bus 13(2):305-338

The Korea Economic Daily (2019) April 22. https://www.hankyung.com/

Korea IT Times (2019) Over half of convenient O2O service of Korea is a white elephant. http://www.koreaittimes.com/news/articleView.html?idxno=90844. Accessed 19 May 2019

Lee D (2018a) Strategies for technology-driven service encounters for patient experience satisfaction in hospitals. Technol Forecast Soc Chang 137(12):118-127

Lee S (2018b) Innovation: from small “i” to large "I". Int J Qual Innov. https://doi. org/10.1186/s40887-018-0022-4

Lee D (2019) Effects of key value co-creation elements in the healthcare system: focusing on technology applications. Serv Bus 13(2):389-417

Lee Y, Han J (2013) The rise of single-person households and changes in consumption patterns. Korea Inst Ind Econ Rev 18(4):1-28

Lee S, Lim S (2018) Living innovation: from value creation to the greater good. Emerald Publishing Limited, Bingley

Lee S, Olson D (2010) Convergenomics: strategic innovation in the convergence era. Gower, Burlington

Lee S, Ribeiro D, Olson D, Roig S (2007) The importance of the activities of service business in the economy: welcome to the service business. Int J Serv Bus 1(1):1-5

Lee S, Lee D, Kim Y (2019) The quality management ecosystem for predictive maintenance in the Industry 4.0 era. Int J Qual Innov 5(4):1-11

Lusch R, Nambisan S (2015) Service innovation: a service-dominant logic perspective. MIS Q 39(1):155-176

Luxton E (2016) 4 billion people still don't have internet access. World Economic Forum. https://www.weforum.org

Merlino J, Raman A (2013) Health care's service fanatics: how the Cleveland Clinic leaped to the top of the patient-satisfaction surveys. Harv Bus Rev 91(5):108-116

MGI (McKinsey Global Institute) (2017) Artificial intelligence: the next digital frontier?. McKinsey \& Company, New York

Ryan A, Trumbull G, Tufano P (2011) A brief postwar history of U.S. consumer finance. Bus Hist Rev 85:461-498

Schneider R (2011) Climate change: an emergency management perspective. Disaster Prev Manage 20(1):53-62

Shostack G (1985) Planning the service encounter. In: Czepiel J, Solomon M, Suprenant C (eds) The service encounter: managing employee/customer interaction in service businesses. Lexington Books, Lexington, MA 
Sindwani R, Goel R (2015) Technology based self-service banking service quality evaluation: a graph theoretic approach. Int J Adv Sci Technol 80:1-18

Solomon M, Surprenant C, Czepiel J, Gutman E (1985) A role theory perspective on dyadic interactions: the service encounter. J Mark 49(1):99-111

Sweeney J, Danaher T, McColl-Kennedy J (2015) Customer effort in value cocreation activities: improving quality of life and behavioral intentions of health care customers. J Serv Res 18(3):318-335

United Nations Secretariat (2018) World economic and social survey 2018: frontier technologies for sustainable development. United Nations Publication, New York

Vargo S, Lusch R (2004) Evolving to a new dominant logic for marketing. J Mark 68(1):1-17

Vargo S, Lusch R (2006) Service-dominant logic: what it is, what it is not, what it might be? In: Lusch $\mathrm{R}$,

Vargo S (eds) The service-dominant logic of marketing: dialog, debate, and directions. M.E. Sharpe, Armonk, pp 43-56

Vargo S, Lusch R (2008) Service-dominant logic: continuing the evolution. J Acad Mark Sci 36(1):1-10

Vargo S, Lusch R (2016) Institutions and axioms: an extension and update of service-dominant logic. J Acad Mark Sci 44(5):5-23

Verleye K (2015) The co-creation experience from the customer perspective: its measurement and determinants. J Serv Manage 26(2):321-342

Word Development Report (2016) Digital dividends. The World Bank, Washington, DC

Xie K, Wu Y, Xiao J, Hu Q (2016) Value co-creation between firms and customers: the role of big databased cooperative asset. Inf Manage 53:1034-1048

Xue M, Hitt L, Chen P (2011) Determinants and outcomes of Internet banking adoption. Manage Sci 57(2):291-307

Zhao T, Liu Z (2019) Analysis of one-person households who is young's characteristics in combination with social experience from the perspectives of interaction process in product use, social situation and public space. In: 8th international conference, DUXU 2019, held as part of the 21st HCI international conference, HCII 2019, Orlando, FL. July 26-31. In design, user experience, and usability, pp 557-576 